\title{
Inspirational Women in Surgery: Olga Jonasson, the Legacy of the First Female Chair of an Academic Department of Surgery
}

\author{
Carrie A. Sims ${ }^{1} \cdot$ Joy Leemaster $^{1} \cdot$ Timothy M. Pawlik ${ }^{1}$
}

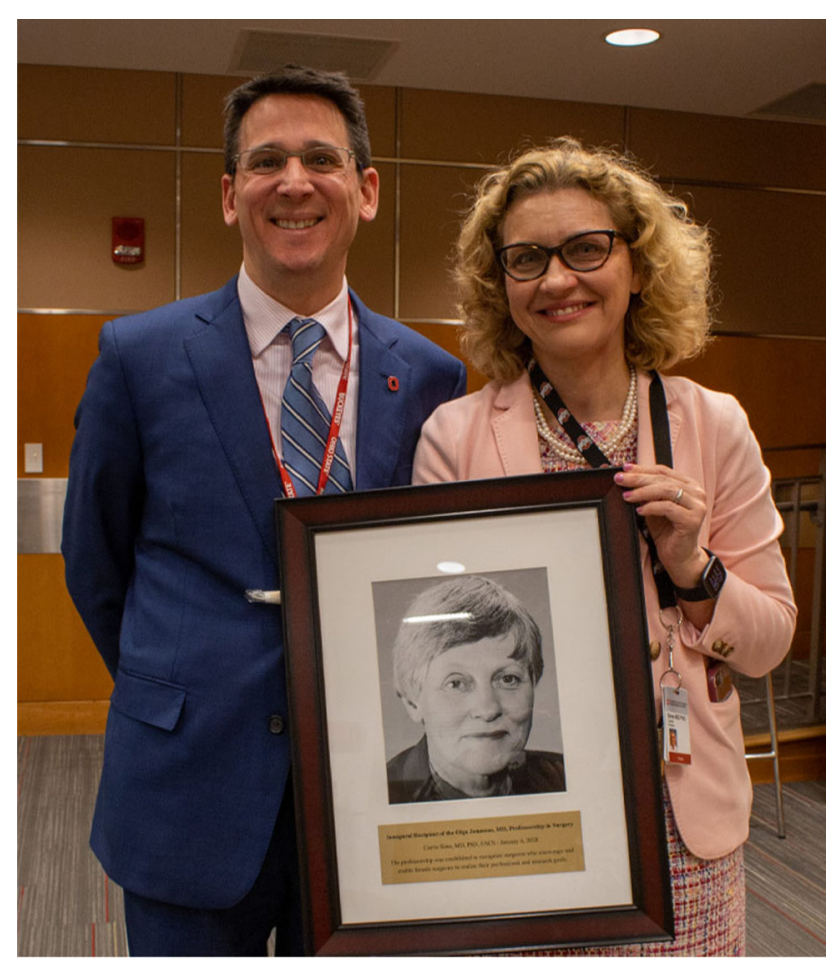

Dr. Olga Jonasson

Without a doubt, Olga Jonasson, MD was one of the most remarkable surgeons in American history and a trailblazer for all women to follow. Born on August 12,

Carrie A. Sims

carrie.sims@osumc.edu

1 Department of Surgery, Wexner Medical Center and James Comprehensive Cancer Center, The Ohio State University, 395 W. 12th Ave., Suite 654, Columbus, OH, USA
1934 in Peoria, Illinois to August and Elsa (Andersdotter) Jonasson, her interest in medicine was sparked by her mother's nursing career and the time she spent with her clergyman father visiting sick parishioners in the hospital. During her childhood in Chicago with two siblings, Dr. Jonasson attended Lyman Trumbull Elementary School and North Park Academy. When her family moved to Connecticut, she stayed behind to attend Northwestern University. She was just 16 years old.

Dr. Jonasson earned her undergraduate degree from Northwestern University in 1956. She graduated with honors from the University of Illinois College of Medicine in 1958, where she first articulated her desire to become a surgeon. This was a particularly bold statement at a time when women, routinely referred to as "lady doctors," accounted for approximately $6 \%$ of all physicians.

After initially declaring her idea "absurd," Jonasson's chief, Warren Cole, MD, became her mentor. He urged her to gain additional research training to prepare for an academic career, and in 1964, she completed her graduate medical education in surgery at the University of Illinois Research and Education Hospital. Her first postgraduate fellowship in immunohistochemistry was at Walter Reed Army Hospital, followed by transplant immunobiology at the Massachusetts General Hospital; she completed a cardiovascular and thoracic fellowship in Chicago. Dr Jonasson would go on to be the first woman transplant surgeon and established the division of transplantation at the University of Illinois at Chicago in 1968.

In 1976, Dr. Jonasson became the first woman to sit on the Board of Regents at the American College of Surgeons and in 1977, and she was named chief of surgery of Cook County Hospital. This made her the first women to be appointed chief of surgery of a major hospital. In 1987, she 
broke yet another barrier when she joined The Ohio State University as the Chair of Surgery, becoming the first woman in the USA to head an academic surgery department.

Dr. Jonasson was known as an excellent educator and fierce champion of resident and medical student well-being. She was bold enough to highlight issues a quarter of a century ago that are now at the forefront of medicine. Dr. Jonasson also emphasized the importance of humanitarian care regardless of gender, ethnicity or religion. In a 1993 lecture to the Clinical Congress of the American College of Surgeons (ACS) titled "Recapturing the joy of surgery," Dr. Jonasson emphasized the need to protect surgeons from "an epidemic of burnout," which could cause emotional exhaustion and a surgeon's "tendency to treat colleagues or patients as objects." Her words reflect the surgical community's current need to protect surgeons from burnoutparticularly during the COVID-19 pandemic-recognizing that surgeon wellness and self-care are important to the future of our health care system.

Dr. Jonasson was a true visionary leader-all the more inspiring because she served at a time when the glass ceiling was particularly tough to break. Dr. Jonasson did all of this with grace, tenacity, humility and shear intellectual brilliance. Historically, surgery has been one of the more challenging specialities for women to rise as leaders, and we are proud that the Ohio State was the first to support this revolutionary change. As such, the Ohio State University Department of Surgery established the Olga Jonasson, MD, Surgical Professorship in August 2019 to recognize academic surgeons who are dedicated to encouraging and enabling female surgeons to realize their professional and research goals, just as she did. Dr. Carrie Sims was named the inaugural recipient of the Jonasson Professorship (Figure). This important initiative aims to create the same celebrity around female surgical genius that our society so readily awards to men. We believe a Professorship in Dr. Jonasson's name is a fitting way to honor, respect and amplify the accomplishments of future female leaders at The Ohio State University Medical Center for generations to come.

Publisher's Note Springer Nature remains neutral with regard to jurisdictional claims in published maps and institutional affiliations. 